\title{
Cat-crnp as New Material With Catalytic Properties for 2-chloro-2-propen-1-ol and Ethylene Oligomerizations
}

\author{
Jacek Malinowski
}

University of Gdansk

\section{Dagmara Jacewicz}

University of Gdansk

\section{Artur Sikorski}

University of Gdansk

\section{Mariusz Urbaniak \\ Jan Kochanowski University \\ Przemysław Rybiński}

Jan Kochanowski University

\section{Patrycja Parnicka}

University of Gdansk

\section{Adriana Zaleska-Medynska}

University of Gdansk

Barbara Gawdzik ( $\nabla$ b.gawdzik@ujk.edu.pl)

Jan Kochanowski University

Joanna Drzeżdżon

University of Gdansk

\section{Research Article}

Keywords: chromium(III) complexes, oligomerization, nitrilotriacetate anion, ethylene

Posted Date: March 8th, 2021

DOI: https://doi.org/10.21203/rs.3.rs-279538/v1

License: (1) (i) This work is licensed under a Creative Commons Attribution 4.0 International License. Read Full License

Version of Record: A version of this preprint was published at Scientific Reports on July 26th, 2021. See the published version at https://doi.org/10.1038/s41598-021-94056-0. 


\section{Abstract}

The contemporary search for new catalysts for olefin oligomerization and polymerization is based on the study of coordinating compounds and/or organometallic compounds as post-metallocene catalysts. However known catalysts are suffered by many flaws, among others unsatisfactory activity, requirement of high pressure or instability at high temperatures. In this paper, we present a new catalyst i.e. the crystalline complex compound possesing high catalytic activity in the oligomerization of olefins, such as 2-chloro-2-propen-1-ol and ethylene under very mild conditions (room temperature, 0.12 bar for ethylene oligomerization, atmospheric pressure for 2-chloro-2-propen-1-ol oligomerization). New material - CatCrNP ( [nitrilotriacetato - 1,10-phenanthroline]chromium(III) tetrahydrate) has been obtained as crystalline form of the nitrilotriacetate complex compound of chromium(III) with 1,10-phenanthroline and characterized in terms of its crystal structure by the XRD method and by multi-analytical investigations towards its physicochemical propeties The yield of catalytic oligomerization over Cat-CrNP reached to $213.92 \mathrm{~g} \cdot \mathrm{mmol}^{-1} \cdot \mathrm{h}^{-1} \cdot$ bar $^{-1}$ and $3232 \mathrm{~g} \cdot \mathrm{mmol}^{-1} \cdot \mathrm{h}^{-1} \cdot$ bar $^{-1}$ for the 2-chloro-2-propen-1-ol and ethylene, respectively. Furthemore, the synthesis of Cat-CrNP is cheap, easy to perform and solvents used during preparation are environmentally friendly.

\section{Introduction}

Since the 1990s, when post-metallocene catalysts were invented, research into polymerization catalysts and material and polymer products became more popular and carried out with greater intensity [1, 2]. Nowadays, new materials are sought to act as catalysts for olefin polymerization and oligomerization $[3,4,5]$.

Chromium(III) complex compounds are known as highly active catalysts for olefin oligomerization and polymerization [6]. The chromium(III) cation can be stabilized by various multi-donor ligands such as, for example, $\mathrm{N}$-pyrrolidine pendant donor or $\mathrm{N}, \mathrm{N}, \mathrm{N}$-bis(imino)trihydroquinoline [7,8]. Chromium(III) complex with chloride and $N, N, N$-bis(imino)trihydroquinoline is used as precatalyst and it must be activated by modified methylaluminoxane (MMAO) [8]. The mentioned chromium(III) complex upon activation is used for the polymerization of ethylene at $80^{\circ} \mathrm{C}$ degrees for 1 hour. The product of the polymerization reaction using this catalytic system is polyethylene. One of the possible four-donor ligand which stabilizes metal ions is nitrilotriacetate anion. Amine nitrilotriacetate salts e.g. di-n-butylamine salt of nitrilotriacetic acid are used for removal copper catalyst from poly(2,6-dimethyl-1,4-phenylene oxide) [9], however, according to our best knowledge, there is no reports on the catalytic properties of chromium(III) complex compounds with the nitrilotriacetate anion for oligomerization and polymerization. In addition, nitrilotriacetic acid $\left(\mathrm{H}_{3} \mathrm{NTA}\right)$ was used in the synthesis of polymers in such a way that nitrilotriacetate $\mathrm{Ni}(\mathrm{II})$ complex end- functionalized polystyrene was obtained [10]. The nitrilotriacetate polymer material has been developed and prepared for use in controlled bioconjugation $[11,12,13]$. The complexes of transition metal cations containing a nitrilotriacetic anion are used for the purification and detection of proteins, provided that they have been tagged with oligohistidine $[14,15,16]$. 
Nitrilotriacetatecomplexes with $\mathrm{Mg}^{2+}, \mathrm{Ca}^{2+}, \mathrm{Sr}^{2+}, \mathrm{Ba}^{2+}$ are used as coordination polymers for selftemplating porous carbon electrocatalysts $[17,18,19,20]$. Crystalline complex compounds containing nitrilotriacetate anion and cations: $\mathrm{Mg}^{2+}, \mathrm{Ca}^{2+}, \mathrm{Sr}^{2+}, \mathrm{Ba}^{2+}$ were pyrolyzed at $750{ }^{\circ} \mathrm{C}$ in $\mathrm{Ar}$ atmosphere. ${ }^{17}$ Inorganic particles formed during pyrolysis were tested. These particles are, for example, $\mathrm{MgO}, \mathrm{BaCO}_{3}$ which are carbon-deposited. These investigations allow to understanding the role of metal ions: $\mathrm{Mg}^{2+}$, $\mathrm{Ca}^{2+}, \mathrm{Sr}^{2+}, \mathrm{Ba}^{2+}$ in the formation of morphological diversity of the carbons which constitute electrocatalysts for reduction of oxygen.

In this work, new material possessing catalytic properties for 2-chloro-2-propen-1-ol and ethylene oligomerizations was successfully synthesized. Cat-CrNP is newly obtained nitrilotriacetate complex compound of chromium(III) with 1,10-phenanthroline ([nitrilotriacetato - 1,10 -phenanthroline] chromium(III) tetrahydrate). The nitrilotriacetate chromium(III) complex has been fully characterized by methods: XRD, elemental analysis, IR, MALDI-TOF-MS, potentiometric and conductometric titrations, thermal analysis and scanning electron microscopy. For the first time Cat-CrNP was used as a precatalyst with methylaluminoxane (MMAO-12) as an activator for the oligomerization of 2-chloro-2-propen-1-ol and ethylene.

\section{Methods}

Synthetic procedures

\section{Cat-CrNP synthesis}

To a suspension of nitrilotriacetic acid $\left(0.57 \mathrm{~g}\right.$ in $\left.40 \mathrm{~mL} \mathrm{H} \mathrm{H}_{2} \mathrm{O}\right)$ was added an aqueous potassium hydroxide solution $\left(0.51 \mathrm{~g}\right.$ in $10 \mathrm{~mL} \mathrm{H}_{2} \mathrm{O}$ ) to convert the acid to a highly water soluble salt. An aqueous $\mathrm{CrCl}_{3}$ solution ( $0.54 \mathrm{~g}$ in $10 \mathrm{~mL}$ of water) was added to the reaction solution. An ethanolic solution of 1,10-phenatroline ( $0.54 \mathrm{~g}$ in $25 \mathrm{~mL}$ of ethanol) was then added. The entire process was carried out using a magnetic stirrer, and in the last step, the reaction solution was heated under reflux at a temperature of $50^{\circ} \mathrm{C}$. Cat-CrNP crystallizes within 14 days.

2-Chloro-2-propen-1-ol oligomerization

The oligomerization process of 2-chloro-2-propen-1-ol was carried out in a glass tube with a closed stopper. The entire reaction was carried out under the following conditions: on a magnetic stirrer, under atmospheric pressure, room temperature and under a nitrogen atmosphere. In the first oligomerization step, $3 \mu \mathrm{mol}$ of chromium(III) complex was dissolved in toluene $(2 \mathrm{~mL})$. Then $3 \mathrm{~mL}$ MMAO-12 was added to the resulting toluene solution. In the last step, 2-chloro-2-propene-1-ol was slowly added. The gel product was obtained after 25 minutes of the reaction. The oligomer obtained was dried and weighed to calculate the efficiency of the carried out process.

Ethylene oligomerization 
A solution of the complex as a precatalyst was prepared by dissolving $3 \mu \mathrm{mol}$ of the complex in $2 \mathrm{~mL}$ of toluene in a glass tube located above the magnetic stirrer. The entire oligomerization process was carried out at 0.12 bar, at room temperature and nitrogen atmosphere. In the next reaction stage, $3 \mathrm{~mL}$ of MMAO12 solution was introduced. The solution was allowed to mix for a while, then ethylene was added all the time until the process was complete. The gel product was obtained after 15 minutes of the reaction. The oligomer obtained was dried and weighed to calculate the efficiency of the carried out process.

Physico-chemical characterization

Diffraction data were collected on an Oxford Diffraction Gemini R ULTRA Ruby CCD diffractometer ( $T$ = 295(2) K, MoK ${ }_{a}(\lambda=0.71073 \AA ̊$ ) radiation, Table 1 - see Electronic Supplementary Information) and were reduced using CrysAlis RED software (ver. 1.171.41.16a) [33]. The structures were refined and solved using the SHELX package (ver. 2017/1) [32]. The water molecule including O4W atom has orientation disorders with refined site-occupancy factors equal 0.50(7). $\mathrm{H}$-atoms from water molecules were located on a difference Fourier map and refined with restraints (DFIX command) with $d_{(\mathrm{O}-\mathrm{H})}=0.95 \AA$ and $\mathrm{U}_{\text {iso }}(\mathrm{H})=1.5 \mathrm{U}_{\text {eq }}(\mathrm{O})$, while $\mathrm{H}$-atoms bound to $\mathrm{C}$-atoms were placed geometrically and refined using a riding model with $d_{(\mathrm{C}-\mathrm{H})}=0.93-0.97 \AA$ and $\mathrm{U}_{\text {iso }}(\mathrm{H})=1.2 \mathrm{U}_{\text {eq }}(\mathrm{C})$. All interactions were identified using the PLATON program (ver. 181115) [34].

The ORTEPII, PLUTO-78 and Mercury (ver. 2020.2.0) programs were used to prepare the molecular graphics $[35,36,37]$. A disordered part of the $04 \mathrm{~W}$ water molecule was omitted from the figures, for clarity. Full crystallographic details for title compound have been deposited in the Cambridge Crystallographic Data Center (deposition No. CCDC 2058007) and they may be obtained from www:

http://www.ccdc.cam.ac.uk, e-mail: deposit@ccdc.cam.ac.uk or The Director, CCDC, 12 Union Road, Cambridge, CB2 1EZ, UK.

The title complex was examined by elemental analysis performed on the Vario EL analyzer Cube (CHNS). The analysis of MALDI-TOF-MS was carried out for titled compound and for the polymerization products using the BrukerBiflex III spectrometer. 2,5-Dihydroxybenzoic acid was the matrix used during the recording of spectra. IR spectra were recorded in $\mathrm{KBr}$ pastil ranging from $4000 \mathrm{~cm}^{-1}$ to $600 \mathrm{~cm}^{-1}$. The BRUKER IFS 66 spectrophotometer was used to carry out the measurements. Potentiometric titration was performed on the CerkoLab system, which consisted of the following components: Hamilton syringes with a capacity of $5 \mathrm{~mL}$, a measuring cell and a combined $\mathrm{pH}$ electrode Schott Blue Line 16. Calibration of the electrode was performed using the weighing method. Potentiometric titration was performed at $\mathrm{T}=$ $298.15 \mathrm{~K} \pm 0.10 \mathrm{~K}$. The temperature was controlled by using the Lauda E100 circulation thermostat. Titration systems were prepared as follows: 1) $\mathrm{H}_{3} \mathrm{NTA}(2 \mathrm{mM})$, 2) $\mathrm{Cr}^{3+}(2 \mathrm{mM})+\mathrm{H}_{3} \mathrm{NTA}(2$ $m M)$, 3) $\mathrm{Cr}^{3+}(2 \mathrm{mM})+\mathrm{H}_{3} \mathrm{NTA}(2 \mathrm{mM})+$ phen $(2 \mathrm{mM})$, where $\mathrm{H}_{3} \mathrm{NTA}$ - nitrilotriacetic acid, phen - 1,10phenantroline. A standard solution of sodium hydroxide $(50 \mathrm{mM})$ was used as the titrant. The titrant was added every 60 seconds in an amount of $0.020 \mathrm{~mL}$. The number of steps was 300 . Conductometric titration was carried out on CerkoLab equipment, which included: a conductometric cell $\left(k=0.096 \mathrm{~cm}^{-1}\right.$ HYDROMET), a magnetic stirrer and a $5 \mathrm{ml}$ Hamilton's syringe. The conductivity probe was calibrated 
using potassium chloride solutions with conductivity of $84 \mu \mathrm{S}$ and $200 \mu \mathrm{S}$ purchased commercially from the Hamilton. The titration was carried out at the temperature $298.15 \mathrm{~K} \pm 0.10 \mathrm{~K}$ and controlled by E100 Lauda circulation thermostat. $50 \mathrm{mM} \mathrm{NaOH}$ was applied as the titrant. Titration systems were prepared as follows: 1) $\mathrm{H}_{3}$ NTA $(2 \mathrm{mM})$, 2) $\mathrm{Cr}^{3+}(2 \mathrm{mM})+\mathrm{H}_{3} \mathrm{NTA}(2 \mathrm{mM})$, 3) $\mathrm{Cr}^{3+}(2 \mathrm{mM})+\mathrm{H}_{3} \mathrm{NTA}(2 \mathrm{mM})$ + phen (2mM), where $\mathrm{H}_{3} \mathrm{NTA}$ - nitrilotriacetic acid, phen - 1,10-phenantroline. Thermal analysis (TG) was performed on NETZSCH TG 209 instrument. Measurements were made in the temperature range from $0{ }^{\circ} \mathrm{C}$ to $1000^{\circ} \mathrm{C}$. The mass of samples subjected to thermal analysis was about $5 \mathrm{mg}$. Thermal analysis was carried out in an argon atmosphere. The morphologies of the as-prepared samples were investigated using field-emission SEM (JSM-7610F, JEOL). The differential scanning calorimetry studies were performed using the equipment from Mettler Toledo. The calibration was carried out based on standards for thermal analysis (ind, n-octane). The measurements were conducted in the range from -150 ${ }^{0} \mathrm{C}$ to $500{ }^{\circ} \mathrm{C}$ with the heating rate of $10{ }^{\circ} \mathrm{C} / \mathrm{min}$ in the inert atmosphere. The sample of the oligomer to the measurements was about $5 \mathrm{mg}$. The liquid nitrogen was used to cooling.

\section{Results And Discussion}

Cat-CrNP has been tested and characterized towards its physicochemical propeties by multi analytical methods such as XRD, elemental analysis, IR, MALDI-TOF-MS, potentiometric conductometric titrations, thermal analysis and scanning electron microscopy. Cat-CrNP is new nitrilotriacetate complex compound of chromium(III) with 1,10-phenanthroline (Fig. 1).

The title compound has an interesting structure. Cat-CrNP was obtained as violet-gold crystals. In the crystal of title compound, molecules of nitrilotriacetate complex compound of chromium(III) with 1,10phenanthroline are linked via $\mathrm{C}-\mathrm{H} \cdots \mathrm{O}$ hydrogen bonds and $\pi-\pi$ interactions to produce blocks along baxis, whereas water molecules interact via $\mathrm{O}_{(\text {water) }}-\mathrm{H} \cdots \mathrm{O}_{\text {(water) }}$ interactions to form a centrosymmetric, alternately arranged $\left(\mathrm{H}_{2} \mathrm{O}\right)_{4}$ (cyclic-planar, tetrameric 0-4-A structure) and $\left(\mathrm{H}_{2} \mathrm{O}\right)_{8}$ (cyclic-chair, octameric 08 -I structure) water clusters, which produce tapes extending along a-axis $[21,22,23]$. In the crystal packing, the adjacent blocks and tapes are connected through $\mathrm{C}-\mathrm{H} \cdots \mathrm{O}_{(\text {water) }}$ and $\mathrm{O}_{(\text {water })}-\mathrm{H} \cdots \mathrm{O}$ hydrogen bonds to form a 3D framework structure (Fig. 2).

Elemental analysis of as-prepared Cat-CrNP revealed that it is composed of $\mathrm{C}(44.18 \%), \mathrm{H}(4.51 \%)$ and $\mathrm{N}(8.54 \%)$. Anal. Calcd.: C, $43.91 \%, \mathrm{H}, 4.51 \%, \mathrm{~N}, 8.53 \%$. Thus, experimentally determined composition of the chromium(III) complex compound perfectly fits theoretical findings.

The IR analysis showed that medium intensity stretch band from carboxylic acid occurs at $3440.39 \mathrm{~cm}^{-1}$. In the range $2969.65-2938.75 \mathrm{~cm}^{-1} \mathrm{O}-\mathrm{H}$ stretching vibrations of crystallization water are observed. The range $1684.67-1664.16 \mathrm{~cm}^{-1}$ confirms the presence of $\mathrm{C}=0$ stretching of the carbonyl group. The peak at $444.76 \mathrm{~cm}^{-1}$ corresponds to deformation vibrations $\mathrm{Cr}-\mathrm{N}$.

MALDI-TOF-MS revealed that Cat-CrNP fragments into $\mathrm{M}-\mathrm{COO}$ and $\mathrm{M}-\mathrm{COOH}$. The potentiometric titration has been used to investigate the stability of the title complex compound by Hyperquad program. 
The value of the $\log \beta$ for Cat-CrNP equal to $8.97 \pm 0.05$. The conductometric analysis allow to confirm the composition of the chromium(III) complex compound. The decrease in the conductivity of the solution is maintained to $\mathrm{n}_{\mathrm{NaOH}}: \mathrm{n}_{\mathrm{H} 3 \mathrm{NTA}}=4$, then $\mathrm{n}_{\mathrm{NaOH}}: \mathrm{n}_{\mathrm{H} 3 \mathrm{NTA}}>4$ there is an increase in conductivity. At $\mathrm{n}_{\mathrm{NaOH}}: \mathrm{n}_{\mathrm{H} 3 \mathrm{NTA}}$ equal to 3 the conductivity of the solution is lowered due to the formation of the complex compound.

Cat-CrNP was subjected to thermal analysis using the thermogravimetric method. The analysis of the thermal decomposition of the coordination compound was carried out in the temperature range from $0{ }^{\circ} \mathrm{C}$ to $1000^{\circ} \mathrm{C}$. Cat-CrNP undergoes thermal decomposition in 7 stages. The first stage of decomposition reached the temperature of $80^{\circ} \mathrm{C}$, where the weight loss was $8.23 \%$. In the first stage of thermal analysis, a peak is observed at $62.2^{\circ} \mathrm{C}$, where there was a weight loss of $2.68 \%$. The second stage of thermal decomposition occurred in the temperature range of $80^{\circ} \mathrm{C}$ to $140{ }^{\circ} \mathrm{C}$, where a second peak is observed, weight loss $(1.23 \%)$ at $90.8^{\circ} \mathrm{C}$. The third stage of thermal analysis of Cat-CrNP occurs in the temperature range of $140{ }^{\circ} \mathrm{C}-380^{\circ} \mathrm{C}$. The weight of the sample during the analysis in this temperature range decreased by $24.65 \%$. In further analysis of TG up to $440{ }^{\circ} \mathrm{C}$ a mass loss equal to $10.67 \%$ and a peak at $437.7{ }^{\circ} \mathrm{C}$ is observed, where $2.38 \%$ of the sample mass has been decomposed. Then the sample decomposed in $10.67 \%$ to the temperature of $460^{\circ} \mathrm{C}$ and in the next stage by $35.94 \%$ to $660{ }^{\circ} \mathrm{C}$. In the last stage of decomposition of the sample, the weight loss was $1.53 \%$. Finally, SEM analysis was used for catalysts morphology imaging. As it was shown in Fig. 3, the chromium complex exhibited a plate-like structure with regular edges and smooth surfaces.

Cat-CrNP has been used for the oligomerization of 2-chloro-2-propen-1-ol and ethylene. The oligomers obtained in the oligomerization of 2-chloro-2-propen-1-ol have been characterized by IR. Medium intensity stretch band of the $\mathrm{O}-\mathrm{H}$ group in the oligomer chain participating in hydrogen bonding occurs at 3474.9 $\mathrm{cm}^{-1} . \mathrm{CH}_{2}$ bending vibration in the oligomer chain is confirmed by peaks in the range $1456.84-1401.64$ $\mathrm{cm}^{-1}$. C-O stretching vibration occurs at $1177.54 \mathrm{~cm}^{-1}$. C-Cl bending vibrations in the oligomer chain have been confirmed by the presence of the peak at $575.02 \mathrm{~cm}^{-1}$. MALDI-TOF-MS analysis showed that the oligomer sample contains from 4 to 7 mers in the chain. The oligomerization product of 2-chloro-2propenol was tested for thermal stability. The sample was decomposed in 5 stages. The first stage of decomposition of the sample resulted in a weight loss of $10.21 \%$ and it was recorded up to $140^{\circ} \mathrm{C}$. A peak was recorded in the above-mentioned temperature range at a temperature of $101.1^{\circ} \mathrm{C}$, where the weight loss was $1.18 \%$. The second stage of thermal decomposition of the tested sample resulted in a weight loss of $5.91 \%$ in the temperature range of $140{ }^{\circ} \mathrm{C}-200^{\circ} \mathrm{C}$. In the third stage $24.62 \%$ of the sample decomposed in in the temperature range of $200{ }^{\circ} \mathrm{C}-440{ }^{\circ} \mathrm{C}$. In this interval, a peak was recorded at 236.0 ${ }^{\circ} \mathrm{C}$ (weight loss $\left.1.49 \%\right)$. In the penultimate stage, the sample decomposed in $12.01 \%\left(440{ }^{\circ} \mathrm{C}-750{ }^{\circ} \mathrm{C}\right)$, while in the last stage it was $2.37 \%\left(750^{\circ} \mathrm{C}-1000^{\circ} \mathrm{C}\right)$.

The analysis of samples obtained as a result of ethylene oligomerization confirmed the structure of the product obtained. IR spectrum allow to concluded that peaks at $2924.11 \mathrm{~cm}^{-1}$ confirms strong asymmetric $\mathrm{CH}_{2}$ stretching vibration in the chain of the oligomer. The peak at $2853.22 \mathrm{~cm}^{-1}$ correspond 
with strong symmetrical $\mathrm{CH}_{2}$ stretching vibration. The presence of strong deformations of $\mathrm{CH}_{2}$ in the oligomer chain is confirmed by the peak at $1513.59 \mathrm{~cm}^{-1}$. Peaks in the range $1467.69-1426.22 \mathrm{~cm}^{-1}$ allow to conclude that weak symmetrical deformation of the terminal $\mathrm{CH}_{3}$ occurs in the oligomer chain. The peak at $856.96 \mathrm{~cm}^{-1}$ confirms the presence of $\mathrm{CH}_{2}$ rocking vibration. MALDI-TOF-MS showed that the product of ethylene oligomerization contains from 12 to 24 mers. In order to understand thermal stability of the obtained oligomers, the sample of oligomers was subjected to the thermal analysis. The sample decomposes in 5 steps. In the first stage of $5.17 \%$ undergoes decomposition to $100^{\circ} \mathrm{C}$. Additionally a peak at $83.6^{\circ} \mathrm{C}$ was recorded, where the weight loss was $1.23 \%$. The second step of thermal analysis $\left(100{ }^{\circ} \mathrm{C}-320^{\circ} \mathrm{C}\right.$ ) resulted in $27.83 \%$ weight loss of the sample. The peak at $149.5^{\circ} \mathrm{C}$ was recorded, where the sample weight decreased by $2.15 \%$. In the next stage of thermal analysis $\left(320^{\circ} \mathrm{C}-520^{\circ} \mathrm{C}\right)$ the sample decomposed by $9.38 \%$. The penultimate stage of the sample decomposition was recorded in the temperature range of $520^{\circ} \mathrm{C}-740^{\circ} \mathrm{C}$ (weight loss $6.68 \%$ ). In the last stage of sample decomposition, the sample decreased by $7.08 \%$.

Glass transition temperatures were determined for the products of oligomerization of 2-chloro-2-propen-1ol and ethylene by DSC method. In the case of a sample of the 2-chloro-2-propen-1-ol oligomerization product, the cooling curve records the thermal change $(\mathrm{Tg})$ at $-113^{\circ} \mathrm{C}$, and in the case of the heating curve at $\mathrm{T}=-95^{\circ} \mathrm{C}$. In the case of the ethylene oligomerization product sample, the cooling curve records the thermal change $(\mathrm{Tg})$ at $-109^{\circ} \mathrm{C}$, and in the case of the heating curve at $\mathrm{T}=-91^{\circ} \mathrm{C}$.

The morphology of the 2-chloro 2-propen 1-ol and ethylene oligomers were investigated by SEM, and the results are shown in Fig. 4. SEM images show that oligomers presented small, highly coagulated, and nonuniform particles. According to the literature,[24,25] such a one-dimensional structure might physically provide a better dispersion in the monomers and better exposure of active sites to the reactants thus achieved high catalytic activity $[24,25]$.

The yield of catalytic oligomerization over Cat-CrNP equaled to $213.92 \mathrm{~g} \cdot \mathrm{mmol}^{-1} \cdot \mathrm{h}^{-1} \cdot \mathrm{bar}^{-1}$ and $3232 \mathrm{~g}$ - $\mathrm{mmol}^{-1} \cdot \mathrm{h}^{-1} \cdot$ bar $^{-1}$ for the 2-chloro-2-propen-1-ol and ethylene, respectively. It means that Cat-CrNP is very highly active catalyst for the ethylene oligomerization and it is highly active catalyst for the 2-chloro2-propen-1-ol oligomerization (Figures 5 and 6). Analyzing other chromium(III) complexes with catalytic properties in ethylene oligomerization (Figure 5), it can be concluded that the Cat-CrNP - new catalytic material shows catalytic activity similar to the best precatalysts. Catalytic oligomerization of ethylene over Cat-CrNPs is only a slightly lower than that previously reported for $\left[\mathrm{Cr}\left(\right.\right.$ dipic) $\left.{ }_{2}\right] \mathrm{Hdmbipy} \cdot 2.5 \mathrm{H}_{2} \mathrm{O}$ (3232 and $3798 \mathrm{~g} \cdot \mathrm{mmol}^{-1} \cdot \mathrm{h}^{-1} \cdot \mathrm{bar}^{-1}$, respectively), nonetheless, synthesis of material reported in this work does not require the usage of thrichlormethane and methanol, and precipitation time was shortened from 2 months to 14 days. It should also be noted that the investigated oligomerization processes with the participation of the new material Cat-CrNP proceed in very mild conditions. Although other catalysts with higher catalytic activity values than the catalyst described in this work are known in the literature, but synthesis of Cat-CrNP is very simple, cheap and it crystallizes very quickly, comparing to synthesis 
procedure of commercially available catalysts. In addition, the synthesis uses mainly an environmentally friendly solvent - water.

\section{Conclusions}

This application brings a new concept of using a new coordination compound obtained in a crystalline form as a material with catalytic properties in the oligomerization of ethylene and 2-chloro-2-propen-1-ol. Physicochemical and catalytic properties of Cat-CrNP were fully described in this article. Cat-CrNP crystallizes in the triclinic system. It is thermally decomposed in 7 stages in the range $0{ }^{\circ} \mathrm{C}$ to $1000{ }^{\circ} \mathrm{C}$. While in the MALDI-TOF-MS analysis it fragmented into $\mathrm{M}$ minus $\mathrm{COO}$ and $\mathrm{M}$ minus $\mathrm{COOH}$. Cat-CrNP has high catalytic activity for 2-chloro-2-propen-1-ol and ethylene oligomerizations. The sample of the oligomerization products contains from 4 to 7 mers and from 12 to 24 mers for 2-chloro-2-propen-1-ol and ethylene oligomerizations, respectively. The results described in this article create the prospect of using the new material, Cat-CrNP, as a catalyst in the oligomerization and polymerization reactions of various olefins.

\section{Declarations}

\section{Acknowledgements}

Supported by the Foundation for Polish Science (FNP).

Authors' contributions Conceptualization: J.D., D.J.; Methodology: J.D., D.J.; Investigation: J.M., M.U., P.R., B.G., A.S., P.P; Writing-original draft preparation: J.D., D.J., J.M., A.S., A.Z.-M.; Supervision: J.D., D.J., A.Z.M.;; Funding acquisition: B. G. All authors have read and agreed to the published version of the manuscript.

\section{Competing interests}

The authors declare no competing interests.

\section{References}

1. Johnson, L. K., Killian, C. M. \& Brookhart, M. New Pd (II)-and Ni (II)-based catalysts for polymerization of ethylene and alpha.-olefins. Am. Chem. Soc. 117, 6414-6415 (1995).

2. Gao, J., Yang, B. \& Chen, C. Sterics versus electronics: Imine/phosphine-oxide-based nickel catalysts for ethylene polymerization and copolymerization. Catal. 369, 233-238 (2019).

3. Cui, L. \& Jian, Z. A N-bridged strategy enables hemilabile phosphine-carbonyl palladium and nickel catalysts to mediate ethylene polymerization and copolymerization with polar vinyl monomers. Chem. 11, 6187-6193 (2020). 
4. Rizkin, B. A. \& Hartman, R. L. Supervised machine learning for prediction of zirconocene-catalyzed aolefin polymerization. Eng. Sci.210, 115224 (2019).

5. Kumawat, J., Trivedi, P. \& Gupta, V. K. Role of a multidentate carbonate Donor in $\mathrm{MgCl}_{2}$-supported Ziegler-Natta olefin polymerization catalysis: An experimental and computational approach. Phys. Chem. C. 123, 24501-24510 (2019).

6. Gibson, V. C. \&Spitzmesser, S. K. Advances in non-metallocene olefin polymerization catalysis. Rev. 103, 283-316 (2003).

7. Döhring, A., Göhre, J., Jolly, P. W., Kryger, B., Rust, J. \& Verhovnik, G. P. J. Donor-ligand-substituted cyclopentadienylchromium(III) complexes: a new class of alkene polymerization catalyst. 1. Aminosubstituted systems. Organometallics, 19, 388-402 (2000).

8. Huang, C., Zakharov, V. A., Semikolenova, N. V., Matsko, M. A., Solan, G. A. \& Sun, W. H. A comparative kinetic study of ethylene polymerization mediated by iron, cobalt and chromium catalysts bearing the same N, N, N-bis(imino) trihydroquinoline. Catal. 369, 1-9 (2019).

9. Cooper, G. D. \& Floryan, D. E. 1977, S. Patent No. 4,039,510. Washington, DC: U.S. Patent and Trademark Office.

10. Cho, H. Y. et al. Synthesis of well-defined (nitrilotriacetic acid)-end-functionalized polystyrenes and their bioconjugation with histidine-tagged green fluorescent proteins. Macromolecules, 44, 46724680 (2011).

11. Heredia, K. L. \& Maynard, H. D. Synthesis of protein-polymer conjugates. Biomol. Chem. 5, 45-53 (2006).

12. Schmitt, L., Ludwig, M., Gaub, H. E. \& Tampe, R. A metal-chelating microscopy tip as a new toolbox for single-molecule experiments by atomic force microscopy. J. 78, 3275-3285 (2000).

13. Hilbrig, F., Stocker, G., Schläppi, J. M., Kocher, H. \& Freitag, R. Utilization of group specific ligands in the downstream processingof proteins by affinity precipitation. Food Bioprod. Process. 84, 28-36 (2006).

14. Hart, C., Schulenberg, B., Diwu, Z., Leung, W.-Y. \& Patton, W. F. Fluorescence detection and quantitation of recombinant proteins containing oligohistidine tag sequences directly in sodium dodecyl sulfate-polyacrylamide gels. Electrophoresis, 24, 599-610 (2003).

15. Schmid, E. L., Keller, T. A., Dienes, Z. \& Vogel, H. Reversible oriented surface immobilization of functional proteins on oxide surfaces. Chem.69, 1979-1985 (1997).

16. Nicolas J., Mantovani, G. \& Haddleton, D. M. Living radical polymerization as a tool for the synthesis of polymer-protein/peptide bioconjugates. Rapid Commun. 28, 1083-1111 (2007).

17. Farber, E. M., Ojha, K., Burshtein, T. Y., Hasson, L. \& Eisenberg, D. Understanding the self-templating of hierarchically porous carbon electrocatalysts using Group 2 coordination polymers. Adv. 1 20-33 (2020).

18. Liang, C., Hong, K., Guiochon, G. A., Mays, J. W. \& Dai, S. Synthesis of a large-scale highly ordered porous carbon film by self-assembly of block copolymers. Angew. Chem. Int. 43 5785-5789 (2004). 
19. Zhao, X. P. et al. Silica-templated covalent organic framework-derived Fe-N-doped mesoporous carbon as oxygen reduction electrocatalyst. Mater. 31 3274-3280 (2019).

20. Serrano, J. M. et al. Composition design of block copolymers for porous carbon fibers. Mater. 31 8898-8907 (2019).

21. CrysAlis CCD and CrysAlis RED; Version 1.171.36.24; Oxford Diffraction Ltd.: Yarnton, UK, 2012.

22. Sheldrick, G. M. Crystal structure refinement with SHELXL. Acta Cryst. C, 71 3-8 (2015).

23. Spek, A. L. Structure validation in chemical crystallography. Acta Cryst. D 65, 148-155 (2009).

24. Johnson, C. K. ORTEP II, Report ORNL-5138; Oak Ridge National Laboratory: Oak Ridge, TN, USA, 1976.

25. Motherwell, S. \& Clegg, S. PLUTO-78, Program for Drawing and Molecular Structure; University of Cambridge: Cambridge, UK, 1978.

26. Macrae, C. F. et al. Mercury CSD 2.0-new features for the visualization and investigation of crystal structures. Appl. Crystallogr. 41, 466-470 (2008).

27. Baburao, B., Visco, P. Jr. \& Albu, T. V. Association Patterns in (HF) $)_{m}\left(\mathrm{H}_{2} \mathrm{O}\right)_{n}(m+n=2-8)$ Clusters. J. Phys. Chem. A, 111 7940-7956 (2007).

28. Maeda, S. \& Ohno, K. Structures of water octamers $\left(\mathrm{H}_{2} \mathrm{O}\right)_{8}$ : Exploration on ab initio potential energy surfaces by the scaled hypersphere search method. Phys. Chem. A, 111 4527-4534 (2007).

29. Trzybiński, D. \& Sikorski, A. Solvent-bridged frameworks of hydrogen bonds in crystals of 9 aminoacridinium halides. CrystEngComm, 15 6808-6818 (2013).

30. Zhang, X. H. et al. Selective copolymerization of carbon dioxide with propylene oxide catalyzed by a nanolamellar double metal cyanide complex catalyst at low polymerization temperatures. Polymer, 52 5494-5502 (2011).

31. Qiang, L., Zhifang, G., Lisha, P. \& Xue, X. Zn-Cr double metal cyanide catalysts synthesized by ball milling for the copolymerization of $\mathrm{CO}_{2}$ /propylene oxide, phthalic anhydride/propylene oxide, and $\mathrm{CO}_{2}$ /propylene oxide/phthalic anhydride. Commun. 64 114-118 (2015).

32. Malinowski, J., Jacewicz, D., Gawdzik, B. \& Drzeżdżon, J. New chromium (III)-based catalysts for ethylene oligomerization. Rep. 1016578 (2020).

33. Drzeżdżon, J., Sikorski, A., Chmurzyński, L. \& Jacewicz, D. New type of highly active chromium(III) catalysts containing both organic cations and anions designed for polymerization of beta-olefin derivatives. Rep. 82315 (2018).

34. Drzeżdżon, J., Sikorski, A., Chmurzyński, L. \& Jacewicz, D. Oligomerization of 2-chloroallyl alcohol by 2-pyridinecarboxylate complex of chromium (III)-new highly active and selective catalyst. Rep. 8 8632 (2018).

35. Drzeżdżon, J., Chmurzyński, L. \& Jacewicz, D. Geometric isomerism effect on catalytic activities of bis(oxalato)diaquochromates(III) for 2-chloroallyl alcohol oligomerization. Chem. Sci. 130116 (2018). 
36. Drzeżdżon, J., Zych, D., Malinowski, J., Sikorski, A., Chmurzyński, L. \& Jacewicz, D. Formation of 2chloroallyl alcohol oligomers using a new crystalline dipicolinate complex of $\mathrm{Cr}$ (III) as a catalyst. Catal. 375 287-293 (2019).

37. Malinowski, J., Sikorski, A., Jacewicz, D. \& Drzeżdżon, J. A new complex compound of chromium (III) with 5-aminopyridine-2-carboxylate anions-structure, physicochemical and catalytic properties. Polyhedron, 186114616 (2020).

Figures

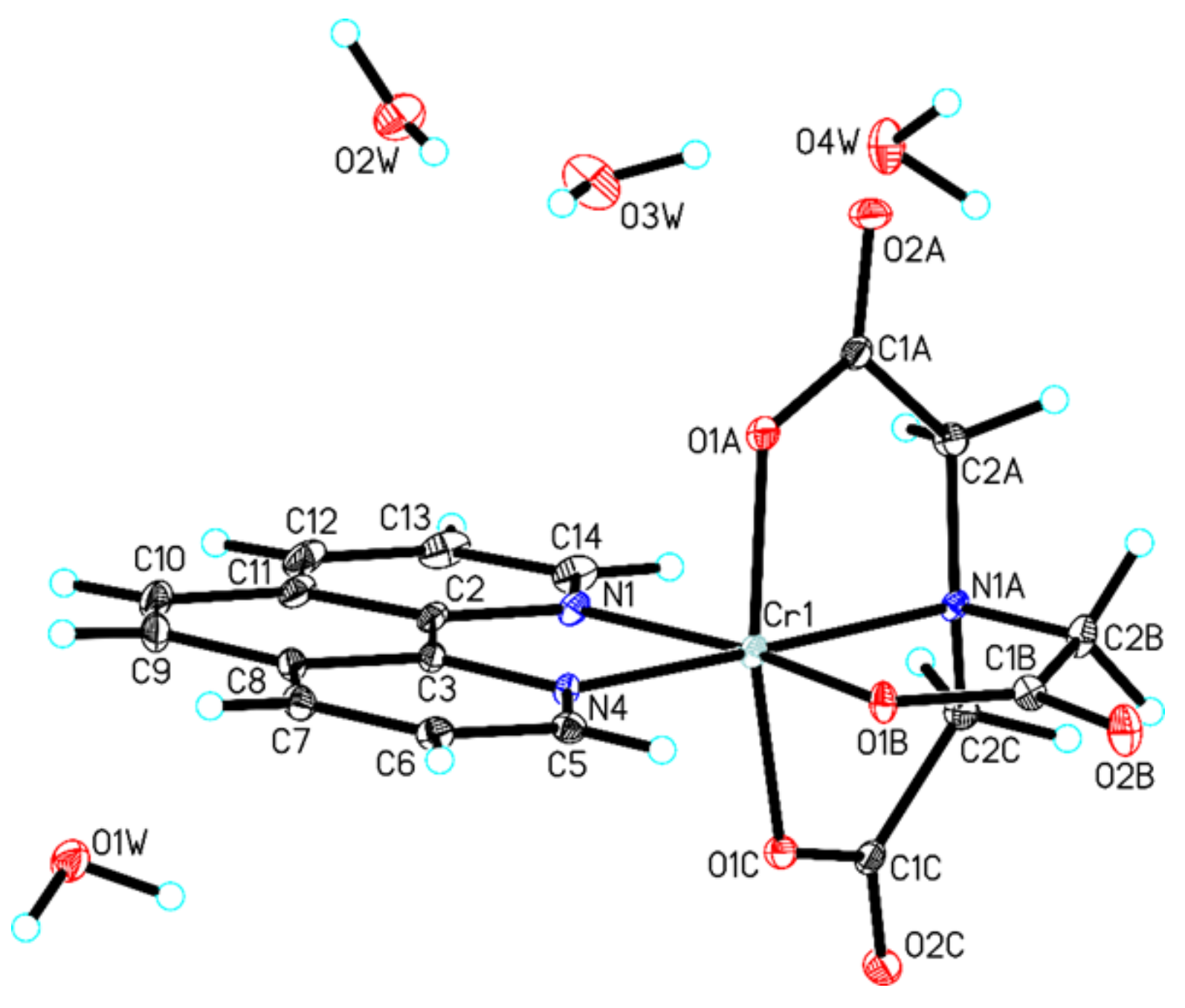

Figure 1

Molecular structure of title compound, showing the atom-labelling scheme (hydrogen bonds are represented by dashed lines). 


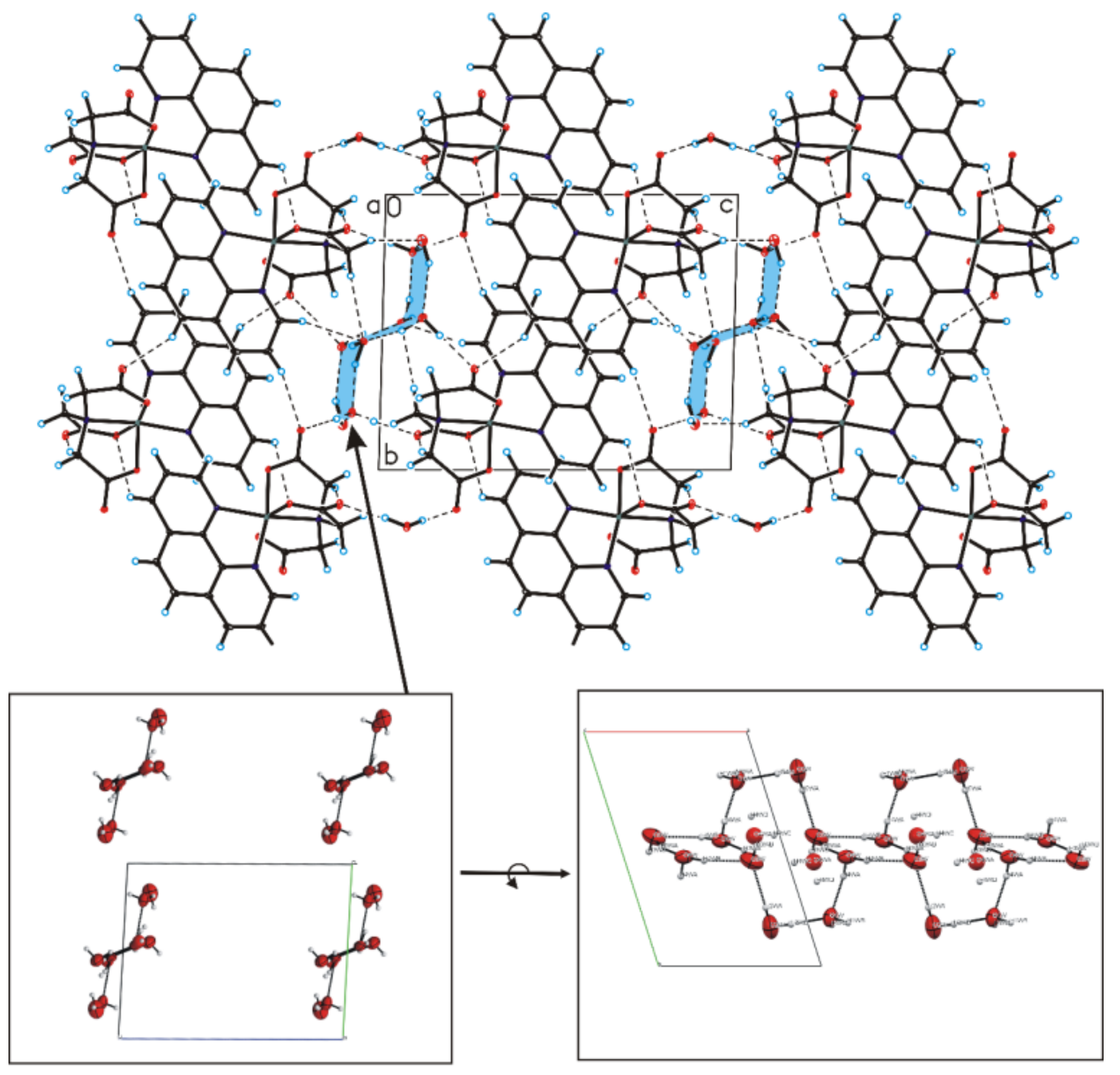

Figure 2

Crystal packing of (nitrilotriacetato - 1,10-phenanthroline)chromium(III) tetrahydrate viewed along a-axis. 

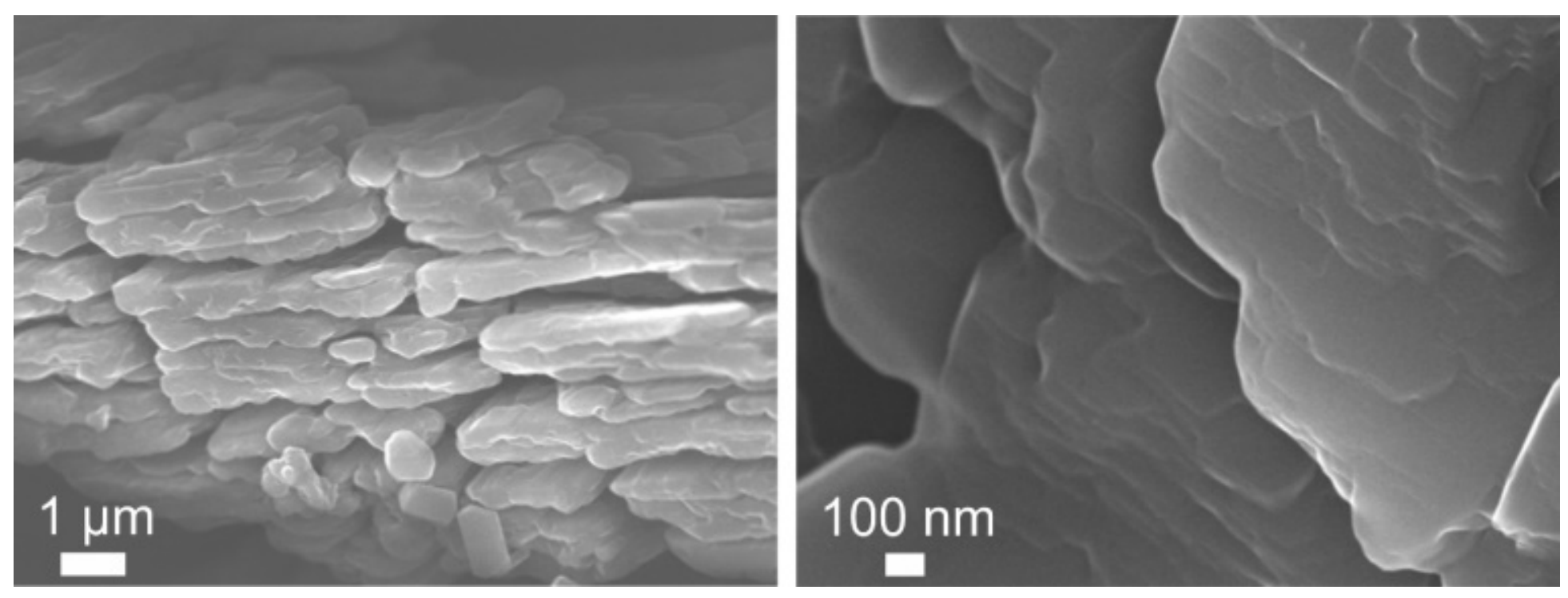

Figure 3

SEM images of Cat-CrNP complex.
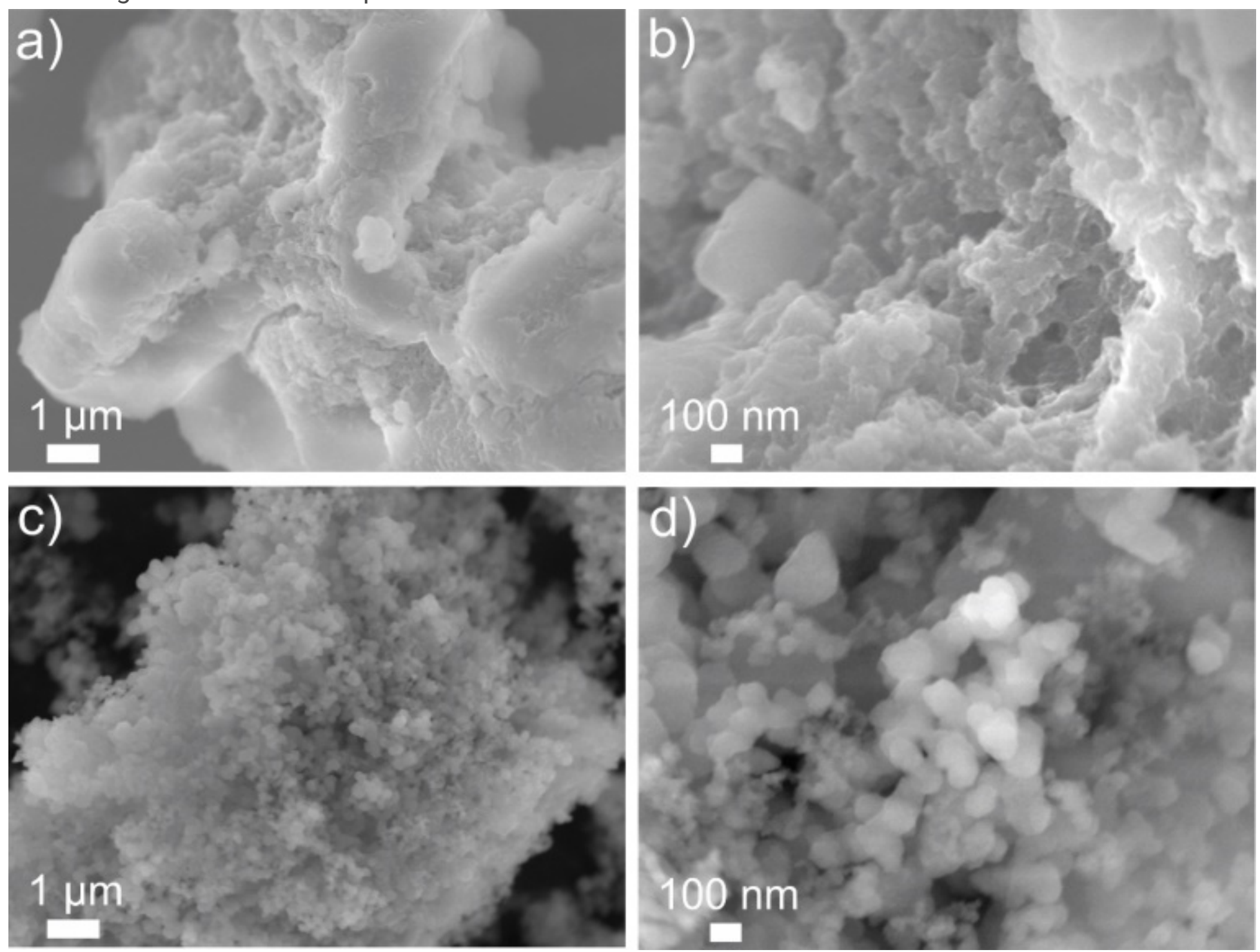

Figure 4 
Low and high magnification SEM images of $(a, b)$ 2-chloro-2-propen-1-ol, and (c, d) ethylene oligomers.

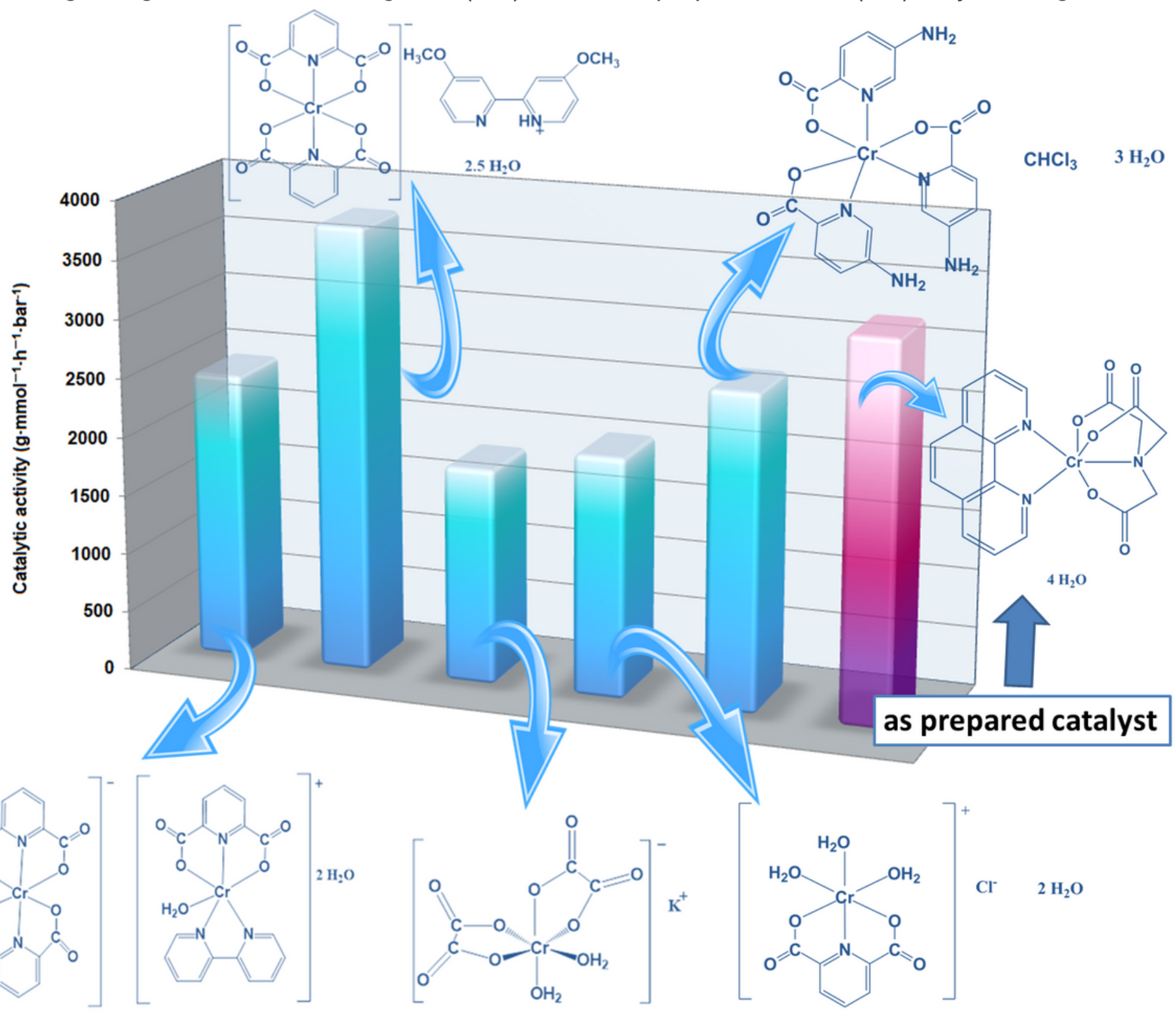

\section{Figure 5}

The catalytic activities of $\mathrm{Cr}(\mathrm{III})$ complexes for ethylene oligomerization based on [32] 


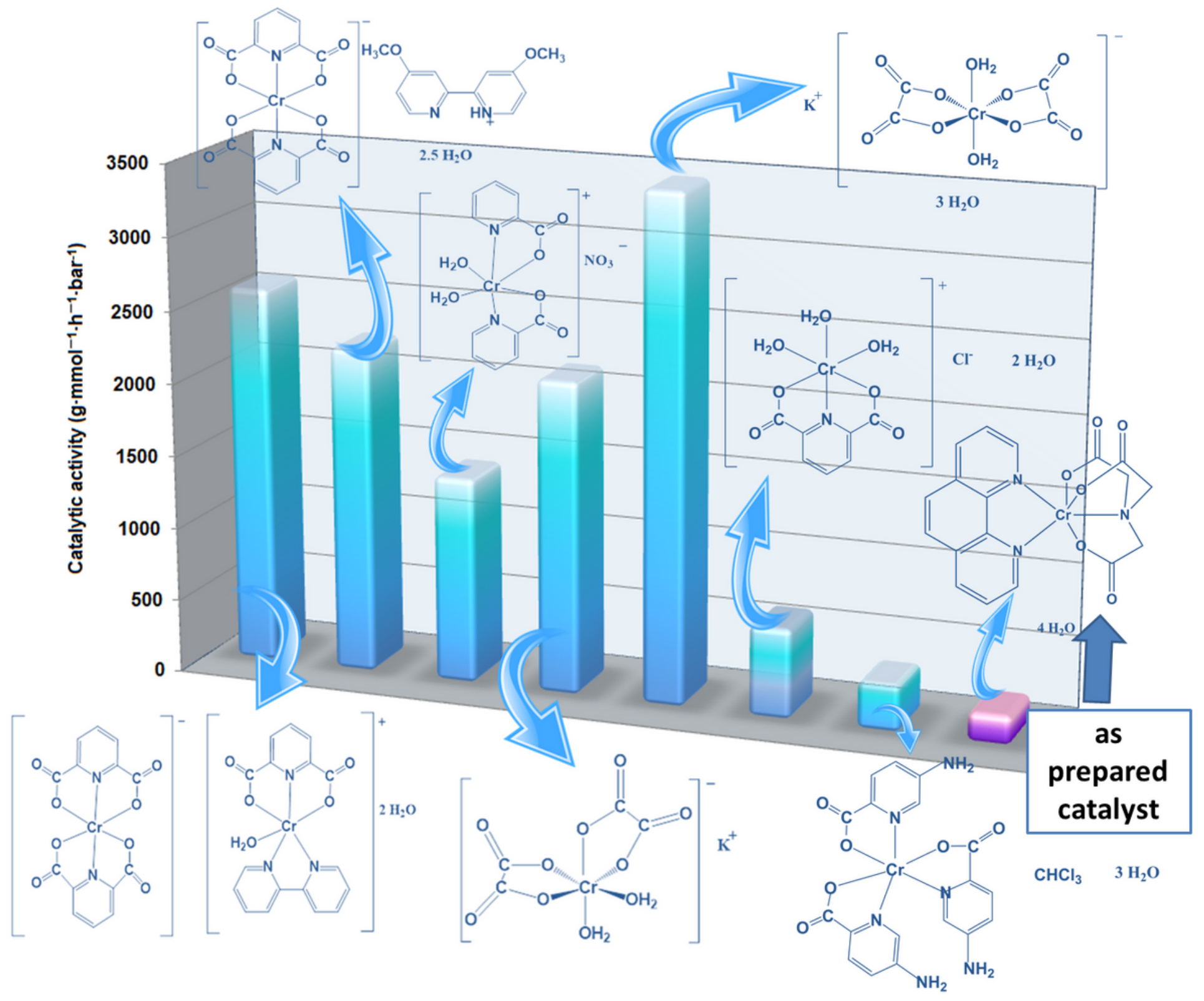

Figure 6

The catalytic activities of $\mathrm{Cr}$ (III) complexes for 2-chloro-2-propen-1-ol oligomerization based on $[33,34,35,36,37]$

\section{Supplementary Files}

This is a list of supplementary files associated with this preprint. Click to download.

- ElectronicSupplementaryInformation.doc 